\title{
A qualitative analysis of virtual patient descriptions in healthcare education based on a systematic literature review
}

\author{
Inga Hege ${ }^{1,6^{*}}$, Andrzej A. Kononowicz ${ }^{2,3}$, Daniel Tolks ${ }^{1}$, Samuel Edelbring ${ }^{3,4}$ and Katja Kuehlmeyer ${ }^{5}$
}

\begin{abstract}
Background: Virtual Patients (VPs) have been in the focus of research in healthcare education for many years. The aim of our study was to analyze how virtual patients are described in the healthcare education literature, and how the identified concepts relate to each other.

Methods: We performed a literature review and extracted 185 descriptions of virtual patients from the articles. In a qualitative content analysis approach we inductively-deductively developed categories and deducted subcategories. We constructed a concept map to illustrate these concepts and their interrelations.

Results: We developed the following five main categories: Patient, Teacher, Virtual Patient, Curriculum, and Learner. The concept map includes these categories and highlights aspects such as the under-valued role of patients in shaping their virtual representation and opposing concepts, such as standardization of learner activity versus learner-centeredness.

Conclusions: The presented concept map synthesizes VP descriptions and serves as a basis for both, VP use and discussions of research topics related to virtual patients.
\end{abstract}

Keywords: Virtual patients, Qualitative content analysis, Concept mapping

\section{Background}

Virtual Patients (VPs) in healthcare education is a broad umbrella term for computer-based programs to simulate real-life clinical scenarios [1]. A body of research literature reports on didactical and technical VP characteristics, and curricular use. VPs can be realized using a wide range of presentations, styles, and configurations [2]. Variations can include aspects such as interactivity, provision of feedback, curricular integration, or case progression [3]. VPs can be delivered in different formats such as virtual worlds, mainly text-based lowinteractive VPs, high-fidelity simulations, or conversational agents. A range of competencies, such as clinical reasoning, communication, or examination skills corresponds to these formats and can be trained with VPs [4].

\footnotetext{
* Correspondence: inga.hege@med.uni-muenchen

${ }^{1}$ Institute for Medical Education, Ludwig-Maximilians-Universität München, Ziemssenstr. 1, München 80336, Germany

${ }^{6}$ Geisel School of Medicine at Dartmouth, Hanover, NH, USA

Full list of author information is available at the end of the article
}

To further describe VPs, researchers have suggested frameworks and categorizations. For example, Huwendiek et al. developed a typology of VPs based on the four categories general, educational, instructional, and technical [5]. More recently, Talbot et al. developed a classification model that categorizes VPs based on nine categories, (e.g. "core technology" and "learner skills evaluated") [6], which Kononowicz et al. further elaborated by applying two categories (technology and competency) to classify the body of literature on VPs [4]. Furthermore, VP design principles that students consider beneficial for their learning have been identified (e.g. relevance, interactivity, specific feedback, and authenticity of the interface and student tasks) [7].

The common thread between such frameworks is that they focus on categories and concepts, but not on how these may influence each other or how they are influenced by their environment or actors. However, these aspects have implications on how teacher design VPs and integrate them into courses, and consequently, how 
students use VPs as learning resources. Therefore, we believe that "zooming out" [8] is important to move forward and elaborate a broader perspective of VPs and their environment filling the gaps between categories with relations. A narrow or limited view focusing on particular VP features may constrain possible holistic learning benefits; an overly visionary and idealistic conceptions considering VPs as "one size fits all" interventions may not be in line with educators' and students' way of using VPs.

Our aim was to follow a broad approach by analyzing descriptions of VPs in the healthcare literature, since the process of introducing and explaining a concept often also involves presenting relations of concepts. We aimed to capture and synthesize these concepts and relations to provide both, an overview for educators on using VPs, and a basis for planning research studies with VPs.

We formulated two research questions to guide our work:

- How are virtual patients described in the healthcare literature?

- How do the identified concepts influence each other?

\section{Methods}

The first step of our study was a literature review to extract text passages that describe virtual patients. This included both, explicit definitions and characterizations of virtual patients. In a second step we applied a qualitative content analysis to synthesize and analyze these descriptions.

\section{Data collection}

We searched PubMed, Scopus, EMBASE, PsycINFO, CINAHL/EBSCO, and ERIC for citations on virtual patients (Additional file 1: PRISMA Checklist). Our search strategy consisted of "virtual patient" or "virtual patients" in the title and/or abstract. Exclusion criteria were the following:

- articles in a language other than English.

- short conference abstracts (less than one page).

- "virtual patient" not mentioned within the articles (only in abstract or title).

- non-educational articles.

We deliberately did not include any related search terms, such as case-based learning, since we considered it essential for our study to focus specifically on the concept of virtual patients.

To ensure a comprehensive search in the literature, we did not use a beginning date cutoff and the last date of inclusion was December 31st, 2014.
From the collection of papers, two authors (AK and $\mathrm{IH})$ extracted the VP descriptions into two separate files and composed a single list by consensus. We included statements characterizing the essence or nature of VPs. The descriptions could be composed of multiple text passages from the manuscript, although most of the descriptions originated from introductions. Any specific VP description, such as a specific type of VP implemented at an author's institution have been excluded.

\section{Qualitative content analysis}

We applied a qualitative content analysis following the approach of Schreier [9] to synthesize and analyze descriptions of virtual patients in the healthcare education literature based on a coding frame we developed for this purpose. The five main categories were developed inductively-deductively; they are stemming from a Simulation-based model developed by Issenberg [10] and our shared understanding of VPs. The categories represent the life-cycle and environment of a VP with the three main actors: the patient, who is in the center and the basis of a VP, the teacher who creates a VP, and the learner who engages with a VP. In addition, we elaborated the VP itself as the learning activity and the curriculum, ie the environment, as main categories. The subcategories were developed in a data-driven approach, for which we used the method of subsumption; three authors (AK, SE, IH) examined the descriptions for relevant concepts and paraphrased them into a subcategory. We reached the point of saturation, after coding $10 \%$ of the descriptions. The final decisions about the subcategories and the point of saturation were made in a discussion (AK, SE, IH). We specified the categories and subcategories with a short description including indicators, examples from the data, and decision rules where necessary.

In a second step, we applied the coding frame to $20 \%$ of the descriptions, which were coded independently by two authors (DT, IH). Inconsistencies were resolved by consensus and the coding frame refined to be more specific in some instances. The coding of the remaining $70 \%$ of the descriptions was done by IH; $20 \%$ of these were double-coded by DT and $80 \%$ were re-coded by IH two months after the initial coding. We did not encounter any inconsistencies at this stage. The following flow chart (Fig. 1) illustrates the process of the analysis.

We documented the data analysis in MS Excel and used color codes to segment the descriptions.

\section{Development of the concept map}

We decided to visualize the identified concepts and relations in a concept map. Concept maps are particularly suitable to visualize the organization of knowledge. They represent a set of concepts and their relations in a way 


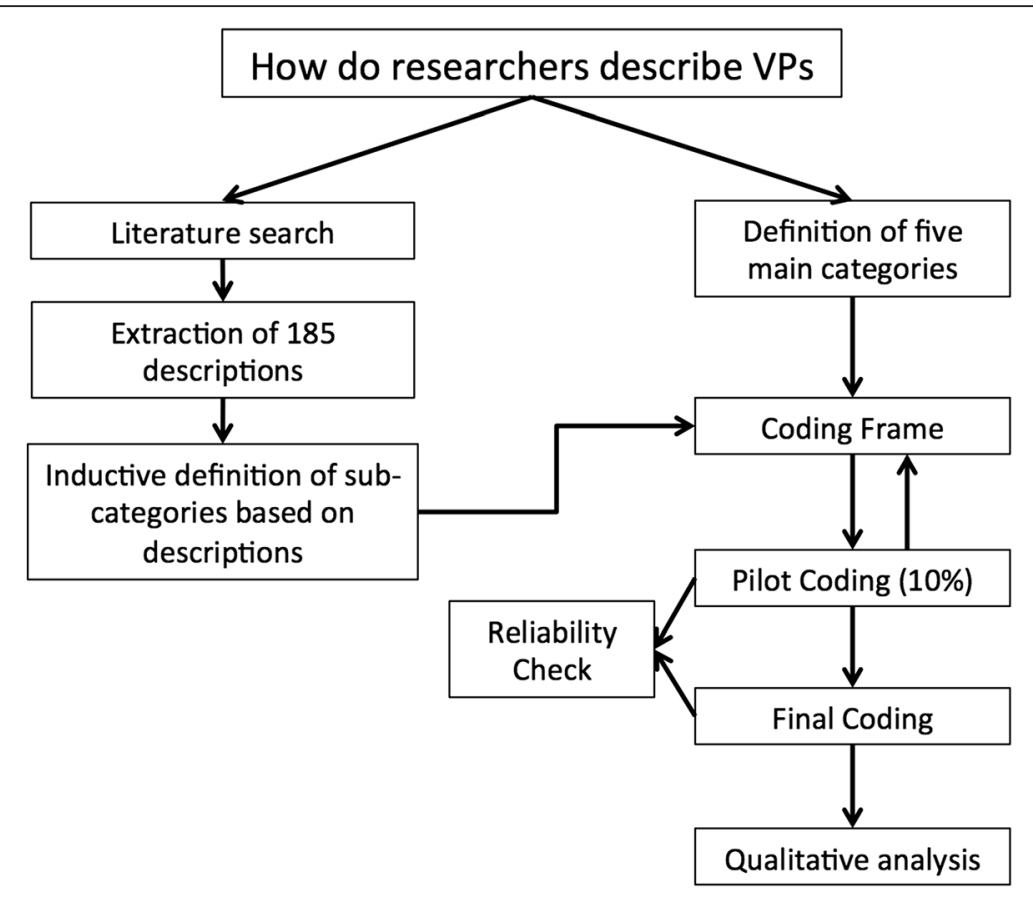

Fig. 1 Process of the study

that new concepts are linked with what is already known [11]. We used the software CMap [12] to construct a concept map that illustrates the concepts (i.e. categories and subcategories) and the relations between them.

\section{Results}

\section{Data collection}

With our search strategy we identified and included 375 educational articles that ranged from 1991 through to the end of 2014 (Fig. 2). From these 375 articles, we extracted 185 descriptions of virtual patients (Additional file 2). The length of the descriptions varied from short paragraphs to page-long descriptions. The remaining 190 articles did not contain any descriptions, mainly because the focus of these articles was not on VPs and therefore the authors did not further describe the VP concept.

\section{Qualitative content analysis}

We defined five main categories: patient, teacher, virtual patient, curriculum, and learner. The subcategories were identified in an inductive approach based on the descriptions. A brief version of the coding guideline is shown in Table 1, the full version can be obtained upon request.

\section{Patient}

The role of patients in the virtual patient creation process was, if at all, described as a deliverer of "authentic video material of real patients" [13] or "(anonymous) patient-related data" [14]. Also, patients were described as not available for bedside-teaching or students do not have access to them (e.g. $[15,16])$, which is one of the reasons why VPs (with almost unlimited availability) were seen as a useful supplement to bedside teaching activities.

\section{Teacher}

The role of teacher or educator in the context of VPs was mainly described as the creator of the virtual patients $[17,18]$.

\section{Documentation}

Teachers can use virtual patient activities to "document the fact that all students have been exposed to all diseases defined by curricular objectives" [14]. VPs "can also easily record student performance and generate reports on individual students" [19].

\section{Resources/costs to create and maintain a VP}

The descriptions included ambiguous information about the resources (i.e. time, effort, and costs) required to develop and deliver VPs. The "process of creating quality VP cases is both expensive and time consuming" [20] and results in "high production costs" [21]. However, in comparison with other teaching activities, authors saw VPs as a cost-effective approach since VPs are "limiting the effort and expense associated with SP [Standardized Patient] training" [22] and "can be delivered at low cost over the internet" [23]. A more differentiated description was provided by Imison et al.: "Branching cases are more difficult 


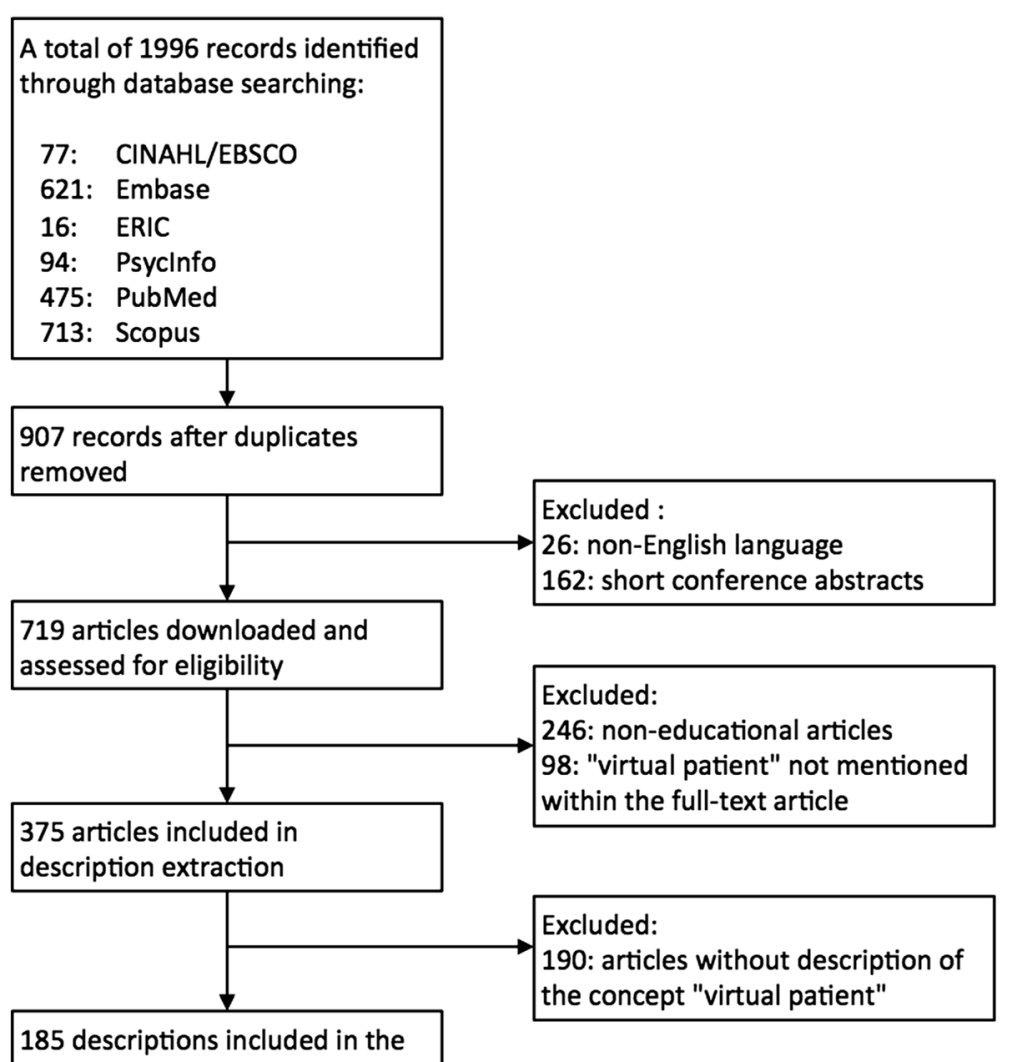

Fig. 2 Process applied to identify descriptions

to construct, more expensive when compared with linear cases" [24]. As a way to lower the effort and production costs, authors described that "medical schools have undertaken efforts to collaboratively develop and use VPs in the recent past" [25] as well as approaches that "have focused on the exchangeability of virtual patients" [26].

\section{Challenges}

Concerning the challenges of developing and using VPs, mainly legal and technical challenges were mentioned. Legal issues included management of rights, permissions, and copyright issues [27, 28]; technical issues were, for example, management of hard- and software, technology support, unreliable internet connection, difficulty in editing a VP, or cross-platform compatibility [27, 29]. Other challenges were low content validity and reliability [30], difficulty of integration into a curriculum [29], and a non-realistic, impersonal, and isolated learning experience [31].

\section{Virtual patient}

\section{Authenticity}

VPs were described as "real life clinical scenarios" [32] and authenticity was described as "critical to whether a virtual patient can be considered to be part of a situated learning endeavor [..]" [33].

\section{Interactivity \& feedback}

VPs "can [...] permit a high level of interactivity" and "fall in the high interactivity range of the continuum [34] but "interaction with these systems also varies greatly" [35]. Posel et al. related the level of interactivity to the navigation model of the VP and concluded that "a branching approach allows the highest level of interactivity" [36]. Immediate feedback in VPs can include "visual and auditory feedback" [37] and "virtual patient platforms can also provide real time clinical guidance" [38] and are "giving the learner automatic feedback on the patient management process" [33].

\section{Variations}

This subcategory encompasses aspects of variability, variety, and adaptability within and across VPs. VPs can "demonstrate a variety of clinical or interview scenarios, for example changing the gender or race of the patient" [20]. They can also be "adapt[ed] quickly to prior knowledge and other individual characteristics of learners" 
Table 1 Categories and subcategories

\begin{tabular}{|c|c|c|}
\hline Category & Subcategories & Definition \\
\hline Patient & & The role the patient plays in a VP \\
\hline \multirow[t]{4}{*}{ Teacher } & & The role of the teacher in VP development and use \\
\hline & Documentation & Tracking and documentation of learner activities and performance \\
\hline & Resources & Resources required to create and implement VPs \\
\hline & Challenges & Challenges a teacher might face when creating or using VPs \\
\hline \multirow[t]{7}{*}{ Virtual Patient } & & Technical and didactical features of VPs \\
\hline & Authenticity & Any aspects related to how realistic VPs are \\
\hline & Interactivity & Any interactive elements implemented in a VP \\
\hline & Feedback & Any kind of feedback that is implemented in a VP (e.g. from VP, tutor, or peers) \\
\hline & Variation & Variation and adaptability of VP design \\
\hline & Technology & Technical aspects of VPs (e.g. scalability or availability). \\
\hline & Instructional design & Design aspects of a VP (e.g. navigation model) \\
\hline \multirow[t]{5}{*}{ Curriculum } & & Relation of a VP to an overall curriculum \\
\hline & Purpose & Purpose of a VP in a curriculum (e.g. a teaching or assessment activity) \\
\hline & Integration & Integration of VPs into a curriculum \\
\hline & Standardization & VPs as a standardization of teaching in medical education \\
\hline & Adoption & Adoption of VPs in healthcare education \\
\hline \multirow[t]{5}{*}{ Learner } & & Learner-related aspects of VPs \\
\hline & Role-Play & Roles the learner plays within a VP scenario \\
\hline & Competency & Competencies that can be trained with VPs \\
\hline & Learner-centeredness & Aspects related to learner as the main focus of a VP activity \\
\hline & Safe Environment & VPs as a risk-free environment for learners and patients. \\
\hline
\end{tabular}

Overview of categories and subcategories derived from the VP descriptions

[39]. "VPs can take different forms" [40], such as avatars in virtual worlds or text-based formats.

\section{Technology}

To describe the underlying technology of VPs researchers used a great variety of terms such as "computer", "web-based", and "simulation", but also "elearning", "virtual reality", or "game". Some researchers described the VP technology in more detail, like the use of "multimedia devices such as still images, video, and audio clips" [41] and user input as well as VP output (e.g. text, speech). The use of mobile devices was included in one description as a medium for VPs [42].

The descriptions also included aspects related to availability and accessibility of patients and VPs. Many factors "limit student exposure to real patients; these include reduced patient time in hospitals, increasing hospital specialization and pressure on clinical budgets." [43]; VPs "can cater to a large number of learners simultaneously and be used by learners repeatedly when needed" [44] "to reach more learners, at more times, in a wider geographic area, than they are able to do through face-to-face contact" [45].

\section{Instructional design}

This subcategory encompasses instructional design aspects of VPs, such as how a learner navigates through a VP. In a linear VP, "the user is prevented from going down any wrong paths by immediate correction" [46]; branched VPs "offer the students various paths to the solution of a case" [14]. However, other terms were used to describe VP navigation, such as "linear-interactive" [47], "knowledge-based contextualization layout" [47], or "algorithm method" [46]. Another categorization of instructional design variations is a problem-solving vs narrative approach. In a problem solving design "information is not 'cued', that is, there is no direction from the program format as to what the student's next course of action should be" [48]; in a narrative design a "personal story line" unfolds following a path in a predefined case [48].

\section{Curriculum \\ Purpose}

Three different aspects - learning (including teaching and training), assessment and self-assessment - were pointed out by the researchers: VPs "have been proposed 
for both training and assessment" [49] and "have also been increasingly utilized for self-assessment" [19].

\section{Curricular integration}

VPs were seen as part of a blended-learning strategy, as "preparation for interaction with SPs and real patients" [22] and to "complement clinical training" [50]. Other potential integration scenarios were the replacement of existing teaching activities with VPs or a learning-byteaching approach $[43,51]$. Curricular integration of VPs was also mentioned as a challenge [52].

\section{Standardization}

Compared to bedside teaching or teaching with standardized patients (SPs), "virtual patients offer true standardization across interactions creating a more consistent but less flexible experience for learners" [53]. "The use of virtual patients can help to standardize the educational value of clinical rotations by exposing all medical students or residents, either through actual clinical cases or through virtual patients, to each classic or important case that is targeted for exposure during the rotation" [45].

\section{Adoption}

Opinions varied about whether VPs are well adopted, an upcoming activity or not (yet) well adopted in healthcare education. Statements ranged from "resulting in lower adoption rates than might be expected" [54], "growth in the use of virtual patients is likely to continue" [39], "VP technology is increasingly used" [55], to VPs are "widely adopted" [56].

\section{Learner}

The target group of VPs were mainly described as students, less often as healthcare professionals. But, also non-healthcare personnel, such as a policemen, firefighters [57], and caregiver or family members of a patient [58] were described as potential learners.

\section{Role-play}

VPs "allow students to adopt the role of a health care provider" [59]. This includes professions such as nurses, dentists, pharmacists and clinicians. However, none of the articles described the potential role of the user as a patient or users playing multiple roles including family members in an inter-professional setting.

\section{Safe environment}

VPs provide a "safe environment for students to practice" [60], "practice making clinical decisions in a safe environment without risk to patients" [31], and lead to "improvement of clinical skills in a non-threatening environment" [29]. It is also noteworthy that researchers pointed out the safety aspect for both, patients and learners: "VP provides practice in a safe environment with no risk to patient or student. Mistakes are allowed [40]".

\section{Learner-centeredness}

Researchers described the use of VPs as "self-paced, independent, and self-directed environment" [34]. VPs "allow for repetitive and deliberate practice" [40] and "there is no time pressure to complete a case, so students may pause, reflect, and choose alternative paths and decisions. [..] Students have the opportunity to repeat their practice and gradually refine their performance" [61].

\section{Competencies}

Competencies that can be addressed by VPs include knowledge acquisition, clinical reasoning, teamwork, communication, and clinical skills training. These competencies are also reflected in the frameworks of Talbot [6] and Kononowicz et al [2]. Additionally, descriptions covered "socio-cultural aspects, trust, respect and empathy" [33].

Researchers pointed out a variety of other characteristics of VPs, such as validity, effectiveness, and reliability of VPs.

\section{Concept map}

Finally, we visualized the relations between the categories and subcategories identified in the analysis in a concept map (Fig. 3).

Figure 3 shows a concept map of the categories and subcategories. Categories are displayed in orange, subcategories in blue, and related concepts in gray. A full-size map is available under http://map.virtualpatients.net.

\section{Discussion}

We synthesized VP descriptions from the healthcare education literature into categories and related concepts and visualized these in a concept map (Fig. 3). This map serves as a basis for the following discussion of categories, concepts, relations, and their implications for both, research and medical education practice.

\section{Patient}

Patients are the center and basis of VPs. However, they do not seem to be regarded and valued as significant actors and their role is often one of a passive receiver of care. This is reflected in the lack of subcategories and only a few relations to other concepts in the concept map. But, patients could be much more involved than being mere donors of material. For example, they could act as reviewers or feedback-givers to ensure that their perspective is adequately represented and valued. Especially when thinking of VPs that present a patient's 


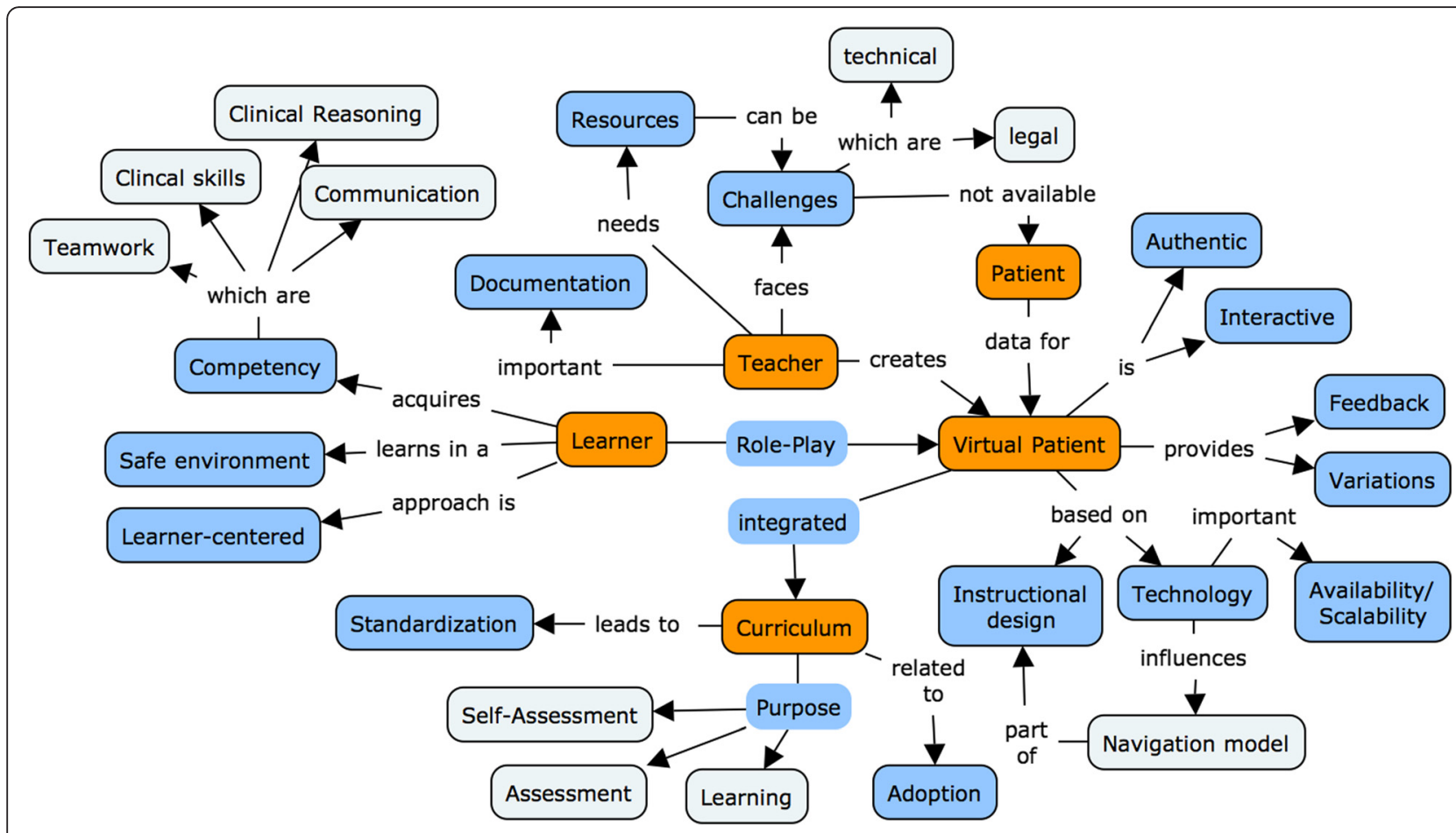

Fig. 3 Concept map

perspective [33], a deeper inclusion of patients into the VP development seems indispensable. Otherwise, we should be concerned about how much we value learning from and with a patient, a concern also raised by Fitzgerald [62].

Future VP development and research should focus on including patients into the VP development beyond multimedia elements and investigate effects on the perceived authenticity of a VP and learner engagement.

\section{Teacher}

Teachers face time, resource, and technical demands, as well as legal challenges when creating and integrating VPs [20]. On the other hand, VPs are supposed to be more time and cost-efficient than other activities, such as SPs [19]. To reduce costs the group of Berman et al. successfully implemented a model to collaboratively develop VPs and share infrastructure costs among institutions [63]. Another initiative, the Electronic Virtual Patients (eViP) project, focused on the exchangeability of virtual patients among different institutions and across VP systems [43, 64]. Educators would benefit from a sophisticated study investigating the multifaceted costs of VP creation, use, and maintenance depending on the underlying VP technology and initiatives for collaborative development or sharing and repurposing VPs.

Despite such challenges, teachers appreciate the fact that their students VP activities and performances are recorded, documented, and can be evaluated for learner and quality assessment purposes. The documented data (such as time spent on a VP or interactions within a VP) can be used for learning analytics and data mining purposes to support the learning processes. However, this raises new issues about data ownership, privacy issues, and disempowerment of learners [65].

\section{Virtual patient}

We subsumed six different aspects under the virtual patient category: technology, authenticity, interactivity, feedback, instructional design, and variations. Although the research focus most often lies in didactical aspects of VPs, the technical basis and variety, ranging from textbased VPs to high-fidelity simulations, are important characteristics that are included in classification frameworks $[4,5]$ and influence the VP look. Consequently, VPs are not homogenous technical artifacts and educators should carefully consider which type of VP aligns best with their learning objectives. Further research is needed to classify characteristic features for specific types of VPs. Availability and scalability play an important role in immersive training environments requiring intensive computational resources [66] or in Massive Open Online Courses (MOOC) [67].

Many concepts of the "Virtual Patient" category have been addressed individually in earlier studies and review articles $[3,36]$ and offer interesting future research questions. For example, the authenticity of a VP (e.g. use of media, interface design, and learner task authenticity) or 
instructional design have been identified as important [7]. But, how exactly these influence the learning and how learners master the step from virtual to real patients remain open questions [13]. It has to be acknowledged that the aspects of this category are interrelated with other concepts. For example, offering variable and adaptable VPs to learners does not yet seem to be widely implemented [59]. Reasons for this lack of flexibility might be technical limitations, a time-consuming creation process, or a contradiction to standardization efforts. An approach to randomize physiological data to quickly produce many slightly different VPs [68] and a framework to integrate computational models into VPs to produce variations of VPs [42] have been suggested to overcome barriers in the creation process. We recommend further studies to identify methods and assess the quality of such semiautomated created VPs and how this affects the creation process, feedback, and level of interactivity. Future research could also focus on the interplay between these aspects, and how that influences learning and learner engagement.

\section{Curriculum}

When offering VPs to learners it is important to consider how they can be integrated into the overall curriculum. Studies have shown that VPs should not be provided as isolated add-ons to a curriculum [69] and that the integration strategy influences student engagement with the VPs [70]. However, there are interesting open research questions and opportunities for innovation. For example, a long-known blendedlearning concept in other content domains, but only recently transferred to medical education, is the flipped or inverted classroom model [71] which can foster critical thinking in students [72]. A few studies $[69,73]$ have been implemented on how to integrate VPs into such an educational setting but, to our knowledge, a large-scale implementation in the curriculum has not yet been described. However, we see an important future research potential in the integration of VPs into inverted classroom scenarios.

Also, for this category, it is important to be aware of the relations to other concepts when integrating VPs into a curriculum: Standardization and assessment to some extent contradict the aspect of a learner-centered and dynamic VP and also the navigation model of a VP influences the degree of standardization. For example, in branched VPs learners can choose diverse learning paths potentially covering different learning objectives.

Different opinions have been expressed when describing how well VPs have been adopted by the medical education community. This is an interesting side-finding which could be followed-up, for example, by conducting surveys among healthcare educators to identify factors that foster or hinder VP uptake.

\section{Learner}

The learners interacts with the VP in a role-play approach; often they are allowed to make their own clinical decisions from the "driver's seat" [74]. According to the descriptions, VPs offer a learner-centered and safe environment in which errors have no negative consequences and deliberate practice is fostered. However, curricular aspects also influence the degree of learner-centeredness and safety of the environment. If using VPs as summative or formative assessment tools, errors do have a consequence for the learner - an aspect that should be carefully considered.

Also, when thinking of a learner-centered embedding of VPs into a curriculum, learners could benefit from collecting and connecting content, learning experiences, feedback, or any other VP-related activity in their personal (e-)portfolio. Portfolios have become widespread in healthcare education in the recent years [75] but to our knowledge little development and research has been done on how to effectively combine them with VP activities.

Learner-centeredness could also be reflected by diversity in role-play, for example, by enabling the learner to choose a role (including the patient's role) in an interprofessional VP setting. The form of the learner's role differs depending on the type of VP and ranges from a written explanation of the scenario and the user's role to the learner steering an avatar in a virtual reality. How this aspect influences learning with a VP or perceived authenticity, especially when looking at different roleplay levels, remains in our opinion an interesting open research question.

The presented concept map highlights the most prevalent and important topics for the VP community. We encourage researchers and educators to use this map as a basis for designing VPs, developing VP systems, and introducing faculty development courses about virtual patients.

\section{Limitations}

Our analysis contributes to an increased awareness of VP characteristics. However, there are several limitations to our study. First, there are other, more general, terms used for VPs, such as patient simulation or computeraided, case-based learning, that have not been included into our analysis. Consequently, we cannot exclude that additional concepts might be revealed when expanding the study to such additional terms. Secondly, our study focused on the body of literature and thereby on the researchers' and educators' views. It is unclear to what extent this also represents other perspectives, such as the 
learners'. Thirdly, we are aware that in qualitative research the subjective perspective of the researchers and the perspectives expressed in the data is interwoven and in retrospective hard to separate.

Finally, as our study aim was to follow a broad approach, we did not present subtle nuances and therefore recommend further, fine-grained research for the subcategories and their relations.

\section{Conclusions}

This paper outlines healthcare education researchers' descriptions of virtual patients structured in five main categories and related concepts. Many of the concepts, especially in the Virtual Patient category, have been considered in existing frameworks and have been researched upon in the past. However, we also point out aspects that have rarely been investigated, such as documentation, standardization of learning activities, or learnercenteredness in VPs. Further research is needed to explore these concepts in more detail.

In the concept map, we visualize concepts related to VPs and their interrelations. We hope that the map will serve as a dynamic resource for both, educators and researchers, and new concepts and relations will be added as research progresses.

The concepts and relations can serve as a basis for structuring a course, formulating learning objectives, evaluation, quality management, and implementing research studies with VPs. We believe that the interactions and relations of the identified concepts have not yet been fully explored and further research is needed. In particular, learner-centeredness seems to be of central importance and is influenced by aspects, such as standardization or interactivity. Finally, we believe that the involvement of learners and patients in virtual patient development and integration should be prioritized in the future.

\section{Ethics approval and consent to participate}

Not applicable.

\section{Consent for publication \\ Not applicable.}

Availability of data and materials

Additional file 2: Extracted definitions (appendix2.pdf).

\section{Additional files}

Additional file 1: PRISMA Checklist. (PDF $123 \mathrm{~kb}$ )

Additional file 2: Extracted definitions. (PDF $671 \mathrm{~kb}$ )

\section{Competing interests}

The authors declare that they have no financial nor non-financial competing interests.

\section{Authors' contributions}

AK and IH planned and implemented the study and drafted the manuscript. DT supported the study implementation, SE gave major input for the study planning, KK provided substantial support for the study as an expert in qualitative research. All authors revised the manuscript critically and gave final approval of the submitted article.

\section{Acknowledgments}

The authors would like to thank Dr. Nabil Zary from the Karolinska Institutet in Stockholm, Sweden for the fruitful discussions which laid the basis for this study. We also would like to thank Diana Ouellette for proof-reading the manuscript.

\section{Funding}

The project received funding from the European Union's Horizon 2020 research and innovation programme under the Marie Skłodowska-Curie grant agreement No 654857.

\section{Author details}

${ }^{1}$ Institute for Medical Education, Ludwig-Maximilians-Universität München, Ziemssenstr. 1, München 80336, Germany. ${ }^{2}$ Department of Bioinformatics and Telemedicine, Faculty of Medicine, Jagiellonian University, Kraków, Poland. ${ }^{3}$ Department of Learning, Informatics Management and Ethics, Karolinska Institutet, Stockholm, Sweden. ${ }^{4}$ Department of Medical and Health Sciences, Linköping University, Linköping, Sweden. Institute for Ethics, History and Theory of Medicine, Ludwig-Maximilians-Universität München, München, Germany. ${ }^{6}$ Geisel School of Medicine at Dartmouth, Hanover, NH, USA.

Received: 31 December 2015 Accepted: 28 April 2016

Published online: 13 May 2016

\section{References}

1. Effective Use of Educational Technology in Medical Education: Summary Report of the 2006 AAMC Colloquium on Educational Technology. Washington: Association of American Medical Colleges; 2007.

2. Ellaway R, Davies D. Design for learning: deconstructing virtual patient activities. Med Teach. 2011;33:303-10.

3. Cook DA, Triola MM. Virtual patients: a critical literature review and proposed next steps. Med Educ. 2009;43:303-11.

4. Kononowicz AA, Zary N, Edelbring S, Corral J, Hege I. Virtual patients-what are we talking about? A framework to classify the meanings of the term in healthcare education. BMC Med Educ. 2015;15:11. doi:10.1186/s12909-015-0296-3.

5. Huwendiek S, De Leng B, Zary N, Fischer MR, Ruiz JG, Ellaway R. Towards a typology of virtual patients. Med Teach. 2009;31:743-8.

6. Talbot TB, Sagae K, John B, Rizzo AA. Sorting out the virtual patient: how to exploit artificial intelligence, game technology and sound educational practices to create engaging role-playing simulations. Int I Gaming Comput-Mediated Simul. 2012:4(3):1-19. doi:10.4018/jgcms.2012070101.

7. Huwendiek S, Reichert F, Bosse HM, de Leng BA, van der Vleuten CPM, Haag M, et al. Design principles for virtual patients: a focus group study among students. Med Educ. 2009:43:580-8.

8. Edelbring $\mathrm{S}$. Research into the use of virtual patients is moving forward by zooming out. Med Educ. 2013:47(6):544-6.

9. Schreier M. Qualitative content analysis in practice. London: SAGE Publications Ltd; 2012.

10. Issenberg SB. The scope of simulation-based healthcare education. Simul Healthcare. 2006:1:203-8.

11. Novak JD, Cañas AJ. The theory underlying concept maps and how to construct and use them. http://cmap.ihmc.us/docs/theory-of-concept-maps Accessed 11 Nov 2015.

12. CMap software. http://cmap.ihmc.us/. Accessed 12 Nov 2015.

13. Triola MM, Huwendiek S, Levinson AJ, Cook DA. New directions in elearning research in health professions education: report of two symposia. Med Teach. 2012:34:e15-20.

14. Kononowicz AA, Hege I. Virtual patients as a practical realisation of the e-learning idea in medicine. In E-learning experiences and future, Safeeullah Soomro (Ed.), ISBN: 978-953-307-092-6, INTECH, Available from: http://sciyo. com/articles/show/title/virtual-patients-as-a-practical-realisation-of-the-elearning-idea-in-medicine 
15. Ellaway R, Poulton T, Fors U, McGee JB, Albright S. Building a virtual patient commons. Med Teach. 2008;30(2):170-4.

16. Johnson TR, Lyons R, Kopper R, Johnsen K, Lok BC, Cendan JC. Virtual patient simulations and optimal social learning context: a replication of an aptitude-treatment interaction effect. Med Teach. 2014;36(6):486-94.

17. El-Razek SMA, El-Bakry HM, El-Wahed WFA, Mastorakis N. Collaborative virtual environment model for medical E-learning. Proceedings of the 9th WSEAS Int. Conf Appl Comput Appl Comput Sci. 2010:191-5.

18. Hooper C. Ethics virtual patients: a new pedagogical tool for educators? J Med Ethics. 2014;0:1-4. doi:10.1136/medethics-2012-101154.

19. Summons PF, Newby D, Athauda R, Park M, Shaw P, Pranata I, Jin JS, XU YD. Design strategy for a scalable virtual pharmacy patient. ACIS 2009 Proceedings. Paper 94

20. Triola MM, Campion N, McGee JB, Albright S, Greene P, Smothers V, et al. An XML standard for virtual patients: exchanging case-based simulations in medical education. AMIA Annu Symp Proc. 2007;11:741-5.

21. Imison M, Hughes C. The virtual patient project: Using low fidelity, student generated online cases in medical education. Proceedings ascilite Melbourne 2008:441-5.

22. Deladisma AM, Cohen M, Stevens A, Wagner P, Lok B, Bernard T, et al. Do medical students respond empathetically to a virtual patient? Am J Surg. 2007;193(6):756-60.

23. Bateman J, Hariman C, Nassrally M. Virtual patients can be used to teach clinical reasoning. Clin Teach. 2012;9(2):133-4.

24. Bateman J, Allen ME, Kidd J, Parsons N, Davies D. Virtual patients design and its effect on clinical reasoning and student experience: a protocol for a randomised factorial multi-centre study. BMC Med Educ. 2012;12:62.

25. Küfner J, Kononowicz AA, Hege I. Virtual patient repositories - a comparative analysis. Stud Health Technol Inform. 2014;205:788-92.

26. Hege I, Zary N, Kononowicz AA. Criteria to assess the quality of virtual patients. Stud Health Technol Inform. 2012;180:954-7.

27. Tan ZS, Mulhausen PL, Smith SR, Ruiz JG. Virtual patients in geriatric education. Gerontol Geriatr Educ. 2010;31(2):163-73.

28. Campbell G, Miller A, Balasubramaniam C. The role of intellectual property in creating, sharing and repurposing virtual patients. Med Teach. 2009;31(8):709-12.

29. Cederberg RA, Bentley DA, Halpin R, Valenza JA. Use of virtual patients in dental education: a survey of U.S. and Canadian dental schools. J Dent Educ. 2012;76(10):1358-64

30. van Bruggen L, Manrique-van Woudenbergh M, Spierenburg E, Vos J. Preferred question types for computer-based assessment of clinical reasoning: a literature study. Perspect Med Educ. 2012;1 (4):162-71.

31. Trace C, Baillie S, Short N. Development and preliminary evaluation of student-authored electronic cases. J Vet Med Educ. 2012;39(4):368-74.

32. Ellaway R, Candler C, Greene P, Smothers V. An Architectural Model for MedBiquitous Virtual Patients. http://groups.medbiq.org/medbiq/display/ VPWG/MedBiquitous+Virtual+Patient+Architecture. Accessed Jan 2015

33. Ekblad S, Mollica RF, Fors U, Pantziaras I, Lavelle J. Educational potential of a virtual patient system for caring for traumatized patients in primary care. BMC Med Educ. 2013;13:110.

34. Posel N. Making a case: Validating criterion-referenced guidelines for virtual patient case authoring. Dissertation Abstracts International Section A: Humanities and Social Sciences. 2012:73(2-A):490.

35. Cendan J, Lok B. The use of virtual patients in medical school curricula. Adv Physiol Educ. 2012;36(1):48-53.

36. Posel N, Fleiszer D. Shore BM.12 tips: guidelines for authoring virtual patient cases. Med Teach. 2009;31(8):701-8.

37. LeFlore JL, Anderson M, Zielke MA, Nelson KA, Thomas PE, Hardee G, et al. Can a virtual patient trainer teach student nurses how to save lives-teaching nursing students about pediatric respiratory diseases. Simul Healthc. 2012;7(1):10-7.

38. Douglass MA, Casale JP, Skirvin JA, Divall MV. A virtual patient software program to improve pharmacy student learning in a comprehensive disease management course. Am J Pharm Educ. 2013;77(8):172.

39. Fletcher JD, Wind AP. Cost considerations in using simulations for medical training. Mil Med. 2013;178(10 Suppl):37-46.

40. Zary N, Johnson G, Boberg J, Fors UG. Development, implementation and pilot evaluation of a Web-based Virtual Patient Case Simulation environment-Web-SP. BMC Med Educ. 2006;6:10.

41. Guise V, Chambers M, Conradi E, Kavia S, Välimäki M. Development, implementation and initial evaluation of narrative virtual patients for use in vocational mental health nurse training. Nurse Educ Today. 2012;32(6):683-9.
42. Kononowicz AA, Narracott AJ, Manini S, Bayley MJ, Lawford PV, McCormack K, et al. A framework for different levels of integration of computational models into web-based virtual patients. J Med Internet Res. 2014;16(1):e23.

43. Poulton T, Balasubramaniam C. Virtual patients: a year of change. Med Teach. 2011;33(11):933-7.

44. Liaw SY, Chan SW, Chen FG, Hooi SC, Siau C. Comparison of virtual patient simulation with mannequin-based simulation for improving clinical performances in assessing and managing clinical deterioration: randomized controlled trial. J Med Internet Res. 2014;16(9):e214.

45. Orton E, Mulhausen P. E-learning virtual patients for geratric education. Gerontol Geriatr Educ. 2008;28(3):73-88.

46. Conradi E, Poulton T, Round J. Teaching decision-making skills through inexpensive virtual scenarios. Proceedings of the 10th IASTED International Conference on Computers and Advanced Technology in Education. 2007;404-9.

47. Botezatu M, Hult H, Tessma MK, Fors UG. Virtual patient simulation for learning and assessment: superior results in comparison with regular course exams. Med Teach. 2010;32(10):845-50.

48. Bearman M. Is virtual the same as real? Medical students' experiences of a virtual patient. Acad Med. 2003;78(5):538-45.

49. Oliven A, Nave R, Gilad D, Barch A. Implementation of a web-based interactive virtual patient case simulation as a training and assessment tool for medical students. Stud Health Technol Inform. 2011;169:233-7.

50. Huang G, Reynolds R, Candler C. Virtual patient simulation at US and Canadian medical schools. Acad Med. 2007:82(5):446-51.

51. Berman N, Fall LH, Smith S, Levine DA, Maloney CG, Potts M, et al, Integration strategies for using virtual patients in clinical clerkships. Acad Med. 2009;84(7):942-9.

52. Stathakarou N, Zary N, Kononowicz AA. Beyond XMOOCs in healthcare education: study of the feasibility in integrating virtual patient systems and MOOC platforms. PeerJ. 2014;2:e672.

53. Triola M, Feldman H, Kalet AL, Zabar S, Kachur EK, Gillespie C, et al. A randomized trial of teaching clinical skills using virtual and live standardized patients. J Gen Intern Med. 2006;21(5):424-9.

54. Bloice MD, Simonic KM, Holzinger A. On the usage of health records for the design of virtual patients: a systematic review. BMC Med Inform Decis Mak. 2013;13(1):103.

55. Bediang G, Franck C, Raetzo MA, Doell J, Ba M, Kamga Y, et al. Developing clinical skills using a virtual patient simulator in a resource-limited setting. Stud Health Technol Inform. 2013;192:102-6.

56. Bateman J, Allen M, Samani D, Kidd J, Davies D. Virtual patient design: exploring what works and why. A grounded theory study. Med Educ. 2013;47:595-606.

57. Fors UG, Muntean V, Botezatu M, Zary N. Cross-cultural use and development of virtual patients. Med Teach. 2009;31(8):732-8.

58. Kenny P, Parsons T, Gratch J, Rizzo A. Virtual humans for assisted health care. 1st International Conference on Pervasive Technologies Related to Assistive Environments. PETRA. 2008

59. Jabbur-Lopes MO, Mesquita AR, Silva LM, De Almeida NA, Lyra DP. Virtual patients in pharmacy education. Am J Pharm Educ. 2012;76(5):92.

60. Consorti F, Mancuso R, Nocioni M, Piccolo A. Efficacy of virtual patients in medical education: a meta-analysis of randomized studies. Comput Educ. 2012;59:1001-8.

61. Friedman SA, Goldschmidt K. Let me introduce you to your first virtual patient. J Ped Nurs. 2014;29:281-3.

62. Fitzgerald F. The virtual Patient. Consultant 360. 2007; 47(8).

63. Berman NB, Fall LH, Chessman AW, Dell MR, Lang VJ, Leong SL, et al. A collaborative model for developing and maintaining virtual patients for medical education. Med Teach. 2011;33(4):319-24.

64. Balasubramaniam C, Poulton T. eViP:Electronic virtual patients. 2008. Print: ISSN1740-8768. Online: ISSN1479-523X.

65. Buckingham Shum S, Ferguson R. Social learning analytics. Educ Technol Soc. 2012;15(3):3-26.

66. Dev P, Heinrichs WL, Youngblood P. CliniSpace ${ }^{\mathrm{TM}}$ : A Multiperson 3D Online Immersive Training Environment Accessible through a Browser. Medicine Meets Virtual Reality 18 J.D. Westwood et al. (Eds.) IOS Press. 2011:173-9

67. Kononowicz AA, Berman AH, Stathakarou N, McGrath C, Bartyński T, Nowakowski $P$, et al. Virtual patients in a behavioral medicine MOOC: a case-based analysis of technical capacity and user navigation pathways. JMIR Medical Education. 2015;1 (2):e8.

68. Tworek J, Pagetti M, McLaughlin K, Wright B. How dungeons \& dragons made us better VPS: randomizing physiological data to rapidly produce 97 clinically realistic VPS. Bio-Algorithms and Med-Systems. 2010;6(11):41-5. 
69. Edelbring S, Broström O, Henriksson P, Vassiliou D, Spaak J, Dahlgren LO, et al. Integrating virtual patients into courses: follow-up seminars and perceived benefit. Med Educ. 2012;46:417-25.

70. Hege I, Kopp V, Adler M, Radon K, Mäsch G, Lyon H, et al. Experiences with different integration strategies of case-based e-learning. Med Teach. 2007; 29(8):791-7.

71. Lage MJ, Glenn JP, Treglia M. Inverting the classroom: a gateway to creating an inclusive learning environment. J Econ Educ. 2000;31 (1):30-43.

72. Moraros J, Islam A, Yu S, Banow R, Schindelka B. Flipping for success: evaluating the effectiveness of a novel teaching approach in a graduate level setting. BMC Med Educ. 2015;15:27.

73. Kononowicz AA, Krawczyk P, Cebula G, Dembkowska M, Drab E, Fraczek B, et al. Effects of introducing a voluntary virtual patient module to a basic life support with an automated external defibrillator course: a randomised trial. BMC Med Educ. 2012;12(1):41.

74. Edelbring S, Dastmalchi M, Hult H, Lundberg IE, Dahlgren LO. Experiencing virtual patients in clinical learning: a phenomenological study. Adv Health Sci Educ Theory Pract. 2011;16(3):331-45.

75. Buckley S, Coleman J, Davison I, Khan KS, Zamora J, Malick S, et al. The educational effects of portfolios on undergraduate student learning: a Best Evidence Medical Education (BEME) systematic review. Med Teach. 2009:31:340-55.

\section{Submit your next manuscript to BioMed Central} and we will help you at every step:

- We accept pre-submission inquiries

- Our selector tool helps you to find the most relevant journal

- We provide round the clock customer support

- Convenient online submission

- Thorough peer review

- Inclusion in PubMed and all major indexing services

- Maximum visibility for your research

Submit your manuscript at www.biomedcentral.com/submit 